\title{
Global burden of COVID-19: Situational analyis and review
}

\author{
Addis Adera Gebru ${ }^{\mathrm{j}, 1, \mathrm{~m}, *}$, Tadesse Birhanu ${ }^{\mathrm{b}}$, Eshetu Wendimu ${ }^{\mathrm{c}}$, Agumas Fentahun Ayalew $^{\mathrm{n}}$, \\ Selamawit Mulat ${ }^{\mathrm{d}}$, Hussen Zakir Abasimel ${ }^{\mathrm{e}}$, Ali Kazemi ${ }^{\mathrm{f}}$, Bosenu Abera Tadesse ${ }^{\mathrm{g}}$, \\ Beniam Adera Gebru ${ }^{h}$, Berhanu Senbeta Deriba ${ }^{a}$, Nigus Shimelis Zeleke ${ }^{\mathrm{i}}$, Abebe Gule Girma ${ }^{\mathrm{b}}$, \\ Bulgantsetseg Munkhbat ${ }^{\mathrm{b}}$, Qamar Kassim Yusuf ${ }^{\mathrm{k}}$, Amana Ogeto Luke ${ }^{\mathrm{l}}$ and Dejene Hailu ${ }^{\mathrm{O}}$ \\ ${ }^{a}$ Department of Public Health, College of Health Sciences, Salale University, Fitche, Ethiopia \\ ${ }^{\mathrm{b}}$ Department of Animal Sciences (Specialist on Infectious Diseases), College of Agriculture and Natural Resources, \\ Salale University, Fitche, Ethiopia \\ ${ }^{\mathrm{c}}$ Research and Community Services Vice President, Salale University, Fitche, Ethiopia \\ ${ }^{\mathrm{d}}$ Injibara Woreda Health Office, Regulatory Officer, Injibara, Ethiopia \\ ${ }^{\mathrm{e}}$ Department of Midwifery, College of Health Sciences, Salale University, Fitche, Ethiopia \\ ${ }_{\mathrm{f}}^{\mathrm{f}}$ Department of Health Economics, School of Public Health, Research Center for Environmental Determinants of \\ Health, Kermanshah University of Medical Sciences, Kermanshah, Iran \\ ${ }^{\mathrm{g}}$ Department of Animal Sciences, College of Agriculture and Natural Resources, Salale University, Fitche, Ethiopia \\ ${ }^{\mathrm{h}}$ Addis Ababa City Adminstration Public Procurement and Materials, Addis Ababa, Ethiopia \\ ${ }^{\mathrm{i}}$ Department of Sociology, College of Social Sciences and Humanities, Salale University, Fitche, Ethiopia \\ ${ }^{\mathrm{j} I n t e r n a t i o n a l ~ R e l a t i o n ~ D i r e c t o r a t e ~ D i r e c t o r, ~ S a l a l e ~ U n i v e r s i t y, ~ F i t c h e, ~ E t h i o p i a ~}$ \\ ${ }^{\mathrm{k}}$ Northern Counties Community Empowerment, Garissa, Kenya \\ ${ }^{1}$ Department of Public Health, Reft Valley University, College of Health Sciences, Abichu Campus, Addis Ababa, \\ Ethiopia \\ ${ }^{\mathrm{m}}$ Department of Public Health, College of Health Sciences, Kotebe Metropolitan University, Addis Ababa, Ethiopia \\ ${ }^{\mathrm{n}}$ Department of Public Health, College of Health Sciences, Woldia University, Woldia, Ethiopia \\ ${ }^{\circ}$ Department of Nursing, College of Health Sciences, Salale University, Fitche, Ethiopia
}

\begin{abstract}
.
BACKGROUND: The novel Coronavirus Disease 2019 (COVID-19) is the major public health burden in the world. The morbidity and mortality of the global community due to this disease is dramatically increasing from time to time.

OBJECTIVE: This situational analysis is aimed to analyse prevalence and incidence of COVID-19 and to provide clear information about this disease for the scientific community, stakeholders, healthcare practitioners and decision-makers.

METHODS: The literatures were identified by searching the key relevant and officially known online databases: medRxiv, Google scholar and PubMed. The online databases contain archives of most English biomedical journals and scientific papers published online from 31 December to 3 April 2020 were included. After the literature search, articles were screened independently by two reviewers for eligibility.

RESULTS: The world continents have confirmed a total of 1,202,320 confirmed COVID-19 cases: (51.2\%) in Europe, (27.7\%) in North America, (17.9\%) in Asia, (1.96\%) in South America and at less number of confirmed COVID-19 cases in Africa and Australia which was accounted $0.8 \%$ and $0.5 \%$, respectively. However, this review showed that there was a significant increase in the confirmed COVID-19 cases by 109,555 in Asia, 8,658 in Africa, 332,866 in North America, 20,269 in South America, 568,894 in Europe, 5,051 in Australia and 1,045,403 in the whole world, with the exception of Antartica, during the review period. The overall results showed that there were 1,098,762 cases and 59,172 deaths recorded during the review period. The result zero number of deaths with COVID-19 was observed in 66 countries.
\end{abstract}

\footnotetext{
* Corresponding author: Addis Adera Gebru, Directorate of Director for International Relation and partnership, Department of Public Health, College of Health Sciences, Salale University, Fitche,
}

Salale, Ethiopia. Tel.: +25 198481 1393. E-mail: addisaderagebru @gmail.com. 
CONCLUSION: The review concluded that COVID-19; SARS-CoV-2 is the major public health burden in the world, the morbidity and mortality of global community is dramatically increasing from time to time. Strong collaboration among all sectors and the design of effective prevention and control strategies which include staying home, social/physical distancing, quarantine, testing of suspected patients, isolation and managing of the confirmed cases. Therefore, all countries should implement five major COVID-19 prevention and control programmes as soon as possible at community level.

Keywords: COVID-19, confirmed cases, deaths, prevention and control, review

\section{Introduction}

The word corona virus have been suggested with different scientists; however, novel coronavirus disease 2019 (COVID-19) and "pneumonia" with no language or time restrictions official seen [1]. Coronaviruses are a large group of viruses that are known to infect both humans and animals, and causes respiratory illness in humans with symptoms that range from common colds to much more serious infections. The COVID-19; SARS-CoV-2 spreads faster than its two ancestors, Severe Acute Respiratory Syndrome Coronavirus (SARS$\mathrm{CoV}$ ) and Middle East Respiratory Syndrome Coronavirus (MERS-CoV), but has lower fatality. The global impact of this new epidemic is yet uncertain [2]. Relevant reports have pointed out the novel coronavirus has $80 \%$ homology with SARS $[3,4]$.

The most well-known case of a coronavirus epidemic was Severe Acute Respiratory Syndrome (SARS), which, after first being detected in southern China in 2002, went on to affect 26 countries and resulted in more than 8,000 cases. An outbreak of a pneumonialike illness that started in the Chinese city of Wuhan has put health authorities on high alert around the world. It has led cities to be cordoned off, caused airlines to cancel flights to and from China and has disrupted global supply chains. The new coronavirus named 2019-nCoV is thought to have originated in the food market of the central China metropolis and has since infected more than 6,000 people [5].

The COVID-19 is thought to have originated in the food market of the central China metropolis and has since infected more than 7,500 people. Deaths and cases are likely to rise until the outbreak is contained. Jurisdictions with cases confirmed as of 30 January 2020, 5:30 AM GMT +3:30, about 7,815 Confirmed cases and 170 Deaths worldwide. According to Lai et al. (2020), the staus of confirmed case in Mainland China in 2019 was 170 deaths, 1,370 severe cases, 6,047 confirmed cases and 124 discharged from hospitals [5].

China first reported the outbreak on 31 December 2019 , most of the deaths have been in Hubei province, where Wuhan is the capital. Chinese authorities have restricted some travel to try and stop the illness since 23 January 2019 and China's financial markets remained closed until Monday 3 February 2019 after authorities extended the Lunar New Year holiday break by three days. The confirmed cases in Mainland China by Province are observed evidence for this critical outbreak world wide. The World Health Organisation [5], China office heard the first reports of a previously unknown virus behind a number of pneumonia cases in Wuhan, a city in Eastern China with a population of over 11 million [6].

Since then, the virus has infected more than 5,974 people globally. Although the vast majority of cases are in China, coronavirus has reached as far as the US, France, Australia, Japan, Canada and South Korea. One hundred and thirty-two people have died, with no reported fatalities outside of China. Experts are worried that the virus' mild symptoms will cause those who carry it to unsuspectingly to transmit it too far and fast. A 10-year-old boy was diagnosed with the coronavirus despite showing no symptoms [5].

According to the Wuhan Bureau of Statistics, U.K. Office for National Statistics, U.S. Census Bureau, World Bank, in Wuhan, public transportation and ridehailing services have been suspended, trains and flights from the city have been stopped and inhabitants have been told to leave only for essential reasons. Similar travel restrictions were announced in at least 11 other Chinese cities, impacting more than 40 million people. On 31 December 2019, WHO was alerted to several cases of pneumonia in Wuhan City, Hubei Province of China. The virus did not match any other known virus. This raised concern because when a virus is new, its dynamicity is unknown [6].

One week later, on 7 January 2019 Chinese authorities confirmed that they had identified a new virus. The new virus is a coronavirus, which is a family of viruses that include the common cold, and viruses such as SARS and MERS. This new virus was temporarily named "2019-nCoV". The number of cases of COVID19 outside China has increased 13 fold, and the number 
of affected countries has tripled In the past two weeks. There are now more than 118,000 cases in 114 countries, and 4,291 people have lost their lives. Thousands more are fighting for their lives in hospitals. In the days and weeks ahead, a number of persons are affected and dead in different countries. The novel COVID-19 is the major public health burden in the world. The morbidity and mortality of global community due to this disease is dramatically increasing from time to time. The spread and severity of the virus has been dramatically increasing across the world [5].

The present literature review was aimed to analyse prevalence, and incidence of COVID-19. It provides clear information about this disease for the scientific community, stakeholders and healthcare practitioners and decision-makers in order design effective prevention and control strategies.

\section{Methods}

\subsection{Study area and period}

The literature review was conducted on World Regions from Largest to smallest area are Asia, Africa, North America, South America, Antarctica, Europe and Australia. Five steps were followed to conduct this systematic review which include identifying a clear research objective and search strategies; identifying relevant research articles; selection of research articles; extraction and charting of data; and discussing, analyzing, and summarizing of the results. The scientific publications from 31 December 2019 to 3 April 2020 were included.

\subsection{Data collection and search databases}

The literatures were identified by searching the key relevant and officially known online databases: medRxiv, Google scholar and PubMed. The online databases contain archives of most English biomedical journals. Scientific papers published online by WHO, CDC, each country's Ministry of health, governmental and official media, reports, books and reputable journal published papers, news papers and magazines related and were also included for this analysis. The COVID19 was key search terms were used in this review. Active cases as such currently infected and/or confirmed cases, in mild and sever or critical condition and closed cases including case which had an outcome, recovery, discharged and over all deaths were identified using relevant searching enginees and data bases.
In this review, the confirmed cases in 1 million population, recovered and total death of population at world continents and the difference among countries. Moreover, the research team was identify the percentage of COVID-19 deaths occurring in Hospitals, at home, other health care institutions and newly established poorary COVID-19 emergency management centers, geoghraphic vibration, common characteristics of COVID-19, consequences and to take advantage of health care providers contact and follow the WHO five major prevention and control methods to slow and reduce transmission of COVID-19 across the analyzed world continents.

\subsection{Data collection and analysis}

After the literature search, articles were screened independently by two reviewers for eligibility. A third reviewer was consulted to resolve disagreements. We included studies published in English. The reviewers has independently reviewed the titles, published year and abstracts against eligibility criteria.

\section{Results}

A total of $47,208(100 \%)$ deaths occurred among those with range of 1-200 were occurred in 129 countries $(62.3 \%), 8$ countries $(3.8 \%)$ were more than 100 deaths, two countries $(0.9 \%)$ were from $801-1000$ deaths and only one countries $(0.8 \%)$ were from $401-$ 600 death occurred. However, 66 countries $(31.8 \%)$ had have not any registered deaths within the study period. These deaths had registered based on the daily reported relevant website and other evidence during, before and after 14 days results of COVID-19 diagnostic test evaluation.

Now a day, United states, Spain, China, France, Iran, United Kingdom, and Netherland are experienced to increasing number of death even they have had implementation guideline, practices and rule and regulation related WHO prevention and control methods. Meanwhile, Germany, Belgium, Switzerland, Turkey, Brazile, and seweden also registed countries with high rate of deaths due to COVID-19 from 31 December 2019 to 3 April 2020. Among those countries with no registered a corona virus caused deaths like Ethiopia, Latvia, Kuwait, Reunion, Vietnam, Malta, FaroeIslands, Georgia, Kyrgyzstan, Cambodia, Rwanda, Liechtenstein, Gibraltar, Madagascar, Arube, Monaco, French Guiana, Barbados, Uganda, Macao, French Polymesa, Zambie, 
Djibouti, Bermuda, Guinea, Maldives, New Caledonia, Equatorial Guinea, Eriteria, Haiti, Mongolia, Namibia, Saint Lucia, Dominica, Greenland, Grenada, Libya, Mozambique Seychelles, Suriname, Benin, Eswatini, Guyinea, Bissav Laos Saint Kitts and Nevis, Antiguo and Barbuda, Chad, Centeral Africe Republic, Liberia, Saint Bathelay, Vatican City, Fiji, Montserral, Nepal, Turks and caicosIslands, Aland Island, Bhutan, Belize, British, Virgon Islands, Somalia, Anguilla, Burundi, Sierraleone, Papula New Guinea, Saint Vincent and the Grenadines and Timor-Leste are need great attention with their regional, National and local governments. The 'zero' result means it is not mean that they are free from death; however, they could not registered any death from their confirmed people in the national level.

The result also showed that most of the countries $(62.3 \%)$ death ranges from 1-200 were under high risk to grow up their death, if their community could not implemented the command post of each countries government to slow COVID-19 transmission. For example, Philippines, Ecuador, Romania, Ireland, Algeria, Japan, Dominican Republic Iraq, Egypt, Greece, Peru, Malysia, Norway, Poland, India, Czechia, Morocco, Panama, Mexico, Luxembrig, Serbia, Argentina, San Marino, Pakistan, Israel, Russia, Australia, Ukraine, Hungary, Colombia, Finland, Saudi-Arabia, Chile, Burkina Faso, Slovenia, Albania, Andorra, Lebanon, Bosina and Heregovia, Thailand, Tunisna, North Macedonia, Honduras, Bulgaria, Cryprus, Democratic Republic of the Congo, United Arab Emirates, Lithaunia, Bolivia, Croatna, Camerroon, Cuba, Mauritus, Guladeloupe, South Africa, Estonia, Moldora, Azerbajian, Taiwan, Jordan, Ghana, Trndad and Tobago, Niger Bangladesh, Singapore, Hingkong, Bahrain, Afghanstian, Kazakhstan, Venezuela, Martinique, Paraguay, Jamaica, Mal,i Iceland, Quatar, Costarica, Urugay, Uzbekistan, Nigeria, Belarus, Republic of the Congo, Srilanka, Mentenegro, Jersey, Northern Cryprus, Elsalvador, Tago, Saint martin Syria, Angola, Sudan, Newzerland, Slovakia, Oman, CotedIvore, Senegal, Palestine Brunci Kosovo, Mayottee, Guernsey, Kenya, Isleof Man, Guatemala, The Bahamas, Tanzania, Gabon, Sintmaarten Myamas (Burnia), Cayman Islands, Guyana, Curacao, Zimbawe, Capeverde, Mauritania, Botswana, Nicaragua, and Gambia are presented from those countries need design the urgent information communication centers, waiting areas, legisilation, surevillence, effective outbreak diseases management systems, support with world health professionals and can be targeted and redesigned serious rule and regulation of how slow the transimission of COVID-19 with community support in order to increase community acceptance of and adherence to prevention and control methods of COVID-19 (Table 1).

The results of the review was also indicated the disease are affecting all community without gender, age, ethinicity group, race, Nationality, length, weigth, width and other factors differences. However, there was a major difference in total number of deaths due to COVID19 across continents and countries of the world. Italy with highest number ( $n=, 155 ; 25.5 \%$ ) of COVID-19 deaths recorded when compared with other 18 countries: Spain $(n=9,387 ; 19.9 \%)$, United State $(n=$ $5,115 ; 10.8 \%)$, France $(n=4,025 ; 8.5 \%)$, China ( $n=$ $3,312 ; 7 \%)$, Iran $(n=3,036 ; 6.4 \%)$, Unied Kingdom ( $n=2,352 ; 5 \%)$, Netherland $(n=1,173 ; 2.5 \%)$, Germany $(n=931,2 \%)$, Belgium $(n=828 ; 1.7 \%)$, Switzerland ( $n=488 ; 1 \%)$, Turkey ( $n=277 ; 0.6 \%)$, Sweden $(n=259 ; 0.54 \%)$, Brazil $(n=240 ; 0.5 \%)$, Portugal ( $n=187 ; 0.45 \%)$, South Korea ( $n=169$; $0.32 \%)$, Austria $(n=146 ; 0.3 \%)$, Canada ( $n=111$, $0.2 \%$ ), and Denmarke ( $n=104 ; 0.22 \%$ ). This indicated that COVID-19 were killed the largest number of population in Italy which followed by Spain and United States of America (Fig. 1).

The result zero number of deaths with COVID-19 was observed in 66 countries that don't mean that the health care facilities are excellent or adequately tested all suspected and affected people compared to their own total number of population who are living in each country. This might be due to lack of laboratory dignostic evaluation centers, lack of skilled COVID-19 expertis, low socioeconomic status and weak recording and reporting system. However, the finidng showed that about ten countries had experienced to investigated many people and had confirmed between 100 and 500 confirmed COVID-19 cases in their country, For example, Lativia (446), Kuwait (317), Reunion (281), Vietnam (218), Malta (188), Faroe Islands (173), Kyrgystan (111) and Cobodie (109) and the remain 56 countries with less than 100 confirmed case including Ethiopia with 31 confirmed COVID-19 cases (Table 2).

Table 3 below, showed that the emerging of COVID19 on 31 December 2019 in Wuhan city of China had been seen as Endemic and then transmitted to neighbor countries due to low extent of prevention and this transmittable disease. The majority (95\%) of currently infected patients at active cases were mildly infected and the remain $39,391(5 \%)$ were serious or critical condition related to COVID-19. In closed case, there was about 288,095 (100\%) of cases which had an outcome, among those 228,923 (79\%) were recovered and 
Table 1

Total deaths due to coronavirs disease 2019 from 31 December 2019 to 3 April 2020

\begin{tabular}{|c|c|c|c|c|}
\hline Roll No & Classification of death & No & $\%$ & List of vulnerable countries \\
\hline 1 & Zero $(0)$ & 66 & 31.8 & $\begin{array}{l}\text { Ethiopia, Latvia, Kuwait, Reunion, Vietnam, Malta, FaroeIslands, Georgia, Kyrgyzstan, } \\
\text { Cambodia, Rwanda, Liechtenstein, Gibraltar, Madagascar, Arube, Monaco, French Guiana, } \\
\text { Barbados, Uganda, Macao, French Polymesa, Zambie, Djibouti, Bermuda, Guinea, Maldives, } \\
\text { New Caledonia, Equatorial Guinea, Eriteria,Haiti, Mongolia, Namibia, Saint Lucia, } \\
\text { Dominica, Greenland, Grenada, Libya, Mozambique Seychelles, Suriname, Benin, Eswatini, } \\
\text { Guyinea, Bissav Laos Saint Kitts and Nevis, Antiguo and Barbuda, Chad, Centeral Africe } \\
\text { Republic, Liberia, Saint Bathelay, Vatican City, Fiji, Montserral, Nepal, Turks and } \\
\text { caicosIslands, Aland Island, Bhutan, Belize, British, Virgon, Islands, Somalia, Anguilla, } \\
\text { Burundi Sierraleone, Papula New Guinea, Saint Vincent and Grenadines and Timor-Leste }\end{array}$ \\
\hline 2 & $1-200$ & 129 & 62.3 & $\begin{array}{l}\text { Philippines, Ecuador, Romania, Ireland, Algeria, Japan, Dominican Republic Iraq, Egypt, } \\
\text { Greece, Peru, Malysia, Norway, Poland, India, Czechia, Morocco, Panama Mexico, } \\
\text { Luxembrig Serbia, Argentina, San Marino Pakistan, Israel, Russia, Australia, Ukraine, } \\
\text { Hungary, Colombia, Finland, Saudi-Arabia, Chile, Burkina Faso. Slovenia, Albania, Andorra } \\
\text { Lebanon, Bosina, Heregovia, Thailand, Tunisa, North Macedonia, Honduras Bulgaria } \\
\text { Cryprus Democratic Republic of the Congo, United Arab Emirates, Lithaunia, Bolivia, } \\
\text { Croatna, Camerroon, Cuba, Mauritus Guladeloupe, South Africa, Estonia, Moldora, } \\
\text { Azerbajian, Taiwan, Jordan, Ghana, Trndad and Tobago, Niger, Bangladesh, Singapore, } \\
\text { Hingkong, Bahrain, Afghanstian, Kazakhstan, Venezuela, Martinique, Paraguay, Jamaica, } \\
\text { Mali, Iceland, Quatar, Costarica, Urugay, Uzbekistan, Nigeria, Belarus, Republic of the } \\
\text { Congo, Srilanka, Mentenegro Jersey, Northern Cryprus, Elsalvador, Tago, Saint martin, Syria, } \\
\text { Angola Sudan, Newzerland, Slovakia, Oman, CotedIvore, Senegal, Palestine, Brunci, Kosovo, } \\
\text { Mayottee, Guernsey, Kenya, Isleof Man, Guatemala, Bahamas, Tanzania, Gabon, } \\
\text { Sintmaarten, Myamas (Burnia) Cayman Islands, Guyana, Curacao, Zimbawe, Capeverde, } \\
\text { Mauritania, Botswana, Nicaragua and Gambia }\end{array}$ \\
\hline 3 & $201-400$ & 3 & 1.4 & Turkey, Brazil, Sweden \\
\hline 4 & $401-600$ & 1 & 0.8 & Switzerland \\
\hline 5 & $601-800$ & 0 & 0 & NA \\
\hline 6 & $801-1000$ & 2 & 0.9 & Germany, Belgium \\
\hline 7 & $\geqslant 1001$ & 8 & 3.8 & United State, Italy, Spain, China, France, Iran, United Kingdom, Netherland \\
\hline \multicolumn{2}{|r|}{ Total } & 207 & 100 & \\
\hline
\end{tabular}

Source: British antarctic survey [7].

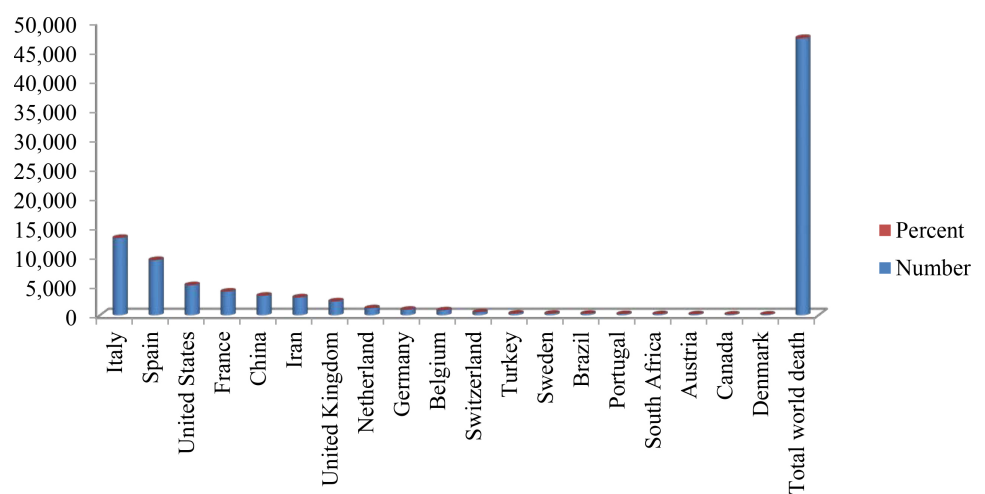

Fig. 1. Percentage of more than 100 number of deaths with COVID-19 in 19 countries from 207 registered COVID-19 vulnerable countries.

discharged from Hospital and other COVID-19 emergency care centers and 59,172 (21\%) died due to the disease. The finding also indicated that there was new cases about 756 in various world nations including the origin of the COVID-19 country, China. Thirty one new deaths has registered in the world continent up to 3 April 2020. Regarding a total cases and deaths in 1 million population were occurred 141.0 and 7.6, respectively.

The overall results showed that there were 1,098,762 cases and 59,172 deaths have recorded from during the review period. The transmission and death rate due to COVID-19 is continues to be major concern for global communities, with the number of people compelled by lack of any option to use five major WHO prevention 
Table 2

Zero death due to Coronavirs Disease 2019 from 31 December 2019 to 3 April 2020

\begin{tabular}{clclcl}
\hline Roll No & Country & Roll No & Roll No & Country & \\
\hline 1 & Ethiopia & 24 & Bermuda & 47 & Chad \\
2 & Latvia & 25 & Guinea & 48 & Centeral Africe Republic \\
3 & Kuwait & 26 & Maldives & 49 & Liberia \\
4 & Reunion & 27 & New Caledonia & 50 & Saint Bathelay \\
5 & Vietnam & 28 & Equatorial Guinea & 51 & Vatican City \\
6 & Malta & 29 & Eriteria & 52 & Fiji \\
7 & FaroeIslands & 30 & Haiti & 53 & Montserral \\
8 & Georgia & 31 & Mongolia & 54 & Nepal \\
9 & Kyrgyzstan & 32 & Namibia & 55 & Turks and caicosIslands \\
10 & Cambodia & 33 & Saint Lucia & 56 & Aland Island \\
11 & Rwanda & 34 & Dominica & 57 & Bhutan \\
12 & Liechtenstein & 35 & Greenland & 58 & Belize \\
13 & Gibraltar & 36 & Grenada & 59 & British Virgon Islands \\
14 & Madagascar & 37 & Libya & 60 & Somalia \\
15 & Arube & 38 & Mozambique & 61 & Anguilla \\
16 & Monaco & 39 & Seychelles & 62 & Burundi \\
17 & French Guiana & 40 & Suriname & 63 & Sierraleone \\
18 & Barbados & 41 & Benin & 64 & Papula New Guinea \\
19 & Uganda & 42 & Eswatini & 65 & Saint Vincent and The Grenadines \\
20 & Macao & 43 & Guyinea Bissav & 66 & Timor-Leste \\
21 & French Polymesa & 44 & Laos & & \\
22 & Zambie & 45 & Saint Kitts and Nevis & & \\
23 & Djibouti & 46 & Antiguo and Barbuda & & \\
\hline
\end{tabular}

Source: [5]

Table 3

Currently infected patients, closed cases, total death and recovered COVID-19 cases WHO world continent from 31 December 2019 to 3 April 2020

\begin{tabular}{cllrr}
\hline $\begin{array}{c}\text { Roll } \\
\text { No }\end{array}$ & Types of cases & Categories & No & $\%$ \\
\hline 1 & Active cases & Currently infected patients & 810,667 & 100 \\
& & In mild condition & 771,276 & 95 \\
& & Serious or critical condition & 39,391 & 5 \\
2 & Closed cases & Cases which had an outcome & 288,095 & 100 \\
& & Recovered/discharged & 228,923 & 79 \\
& & Deaths & 59,172 & 21 \\
3 & New cases & & 756 & \\
4 & New deaths & & 31 & 141.0 \\
5 & Total cases in 1 Million population & 7.6 & \\
6 & Deaths in 1 Million population & $1,098,762$ & \\
7 & Total cases & & 59,172 & \\
8 & Total deaths & & 228,923 & \\
9 & Recovered & & & \\
\hline
\end{tabular}

Source: [8].

and control method of slow COVID-19 transmission. Moreover, the confirmed cases and deaths are inclined from day to day. Hence, the result indicated that the COVID-19 could be exacerbated the impact of world climate change and overburdened health care system and such increase hospitalization with in low number of skilled health professionals. Meanwhile, the result showed that about 228, 923 confirmed COVID-19 patients had recovered from their mild and/or severe condition with strongly supported and significant health care management systems in world countries.
The active cases related to currently infected patient and all confirmed cases in a world continents ability to survive and recovered with effective preventive and control methods and supportive treatments including isolation as best way to slow transmission is assessed, it is clear that COVID-19 is pandemic disease still pose the greatest challenges to the socioeconomic and health of population in the world continents (Table 4). The world continents have confirmed a total of $1,202,320$ confirmed COVID-19 cases: (51.2\%) in Europe, (27.7\%) in North America, (17.9\%) in Asia, (1.96\%) in South America and at less number of confirmed COVID-19 cases in Africa and Australia which was accounted $0.8 \%$ and $0.5 \%$, respectively. However, this review showed that there was significantly increased the confirmed COVID-19 cases by 109,555 in Asia, 8,658 in Africa, 332,866 in North America, 20,269 in South America, 568,894 in Europe, 5,051 in Australia and $1,045,403$ in the whole world continents except Antarctica (WHO, 2020).

Table 5 shows that the world continents have reported number of discharged patients and recovered cases from Hospital and other COVID-19 emergency management centers between 1 January 2020 to 20 March 2020. The total of recovered and discharged at home from various health setting, hospitals and emergency management centers were 245,977 patients out of confirmed a total of 1,202,320 confirmed COVID-19 cases in the world 
Table 4

Confirmed reported cases between 1 January 2020 to 20 March 2020 and 1 Januray 2020 to 3 April 2020 by continent

\begin{tabular}{|c|c|c|c|c|c|}
\hline \multirow{2}{*}{ World continents } & \multicolumn{2}{|c|}{ From 1 January 2020 to 20 March 2020} & \multirow{2}{*}{ COVID-19 Cases On World Map } & \multicolumn{2}{|c|}{1 January 2020 to 3 April 2020} \\
\hline & $\mathrm{No}_{\underline{\mathrm{O}}}$ & $\%$ & & $\mathrm{No}$ & $\%$ \\
\hline Asia & 105,131 & 67.4 & & 214,686 & 17.9 \\
\hline Africa & 308 & 0.2 & & 9,066 & 0.8 \\
\hline North America & 398 & 0.26 & & 333,264 & 27.7 \\
\hline South America & 3,232 & 2.06 & & 23,501 & 1.96 \\
\hline Antartica & 0 & 0 & & 0 & 0 \\
\hline Europe & 46,551 & 29.9 & & 615,445 & 51.2 \\
\hline Australia & 297 & 0.19 & 장 & 5,358 & 0.5 \\
\hline Total & 155,917 & 100 & shuttersteck & $1,201,320$ & 100 \\
\hline
\end{tabular}

Source: [8].

Table 5

Recovery and discharged from hospital and other COVID-19 emergency management centers reports between 1 January 2020 to 20 March 2020 and 1 Januray 2020 to 3 April 2020 by continent

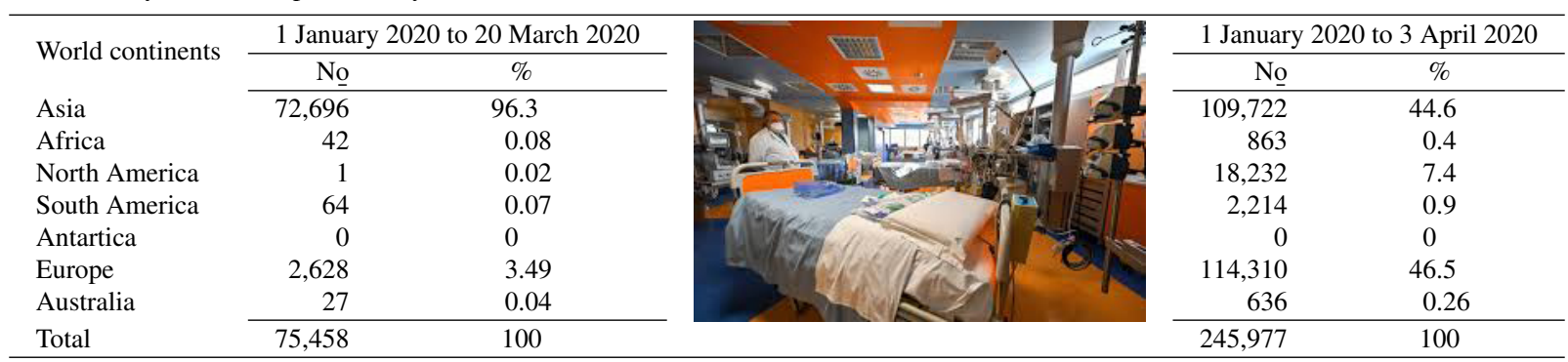

Source: [8].

Notion Except Antartica. From those total of recovered and/or discharged patients, the majority $(46.5 \%)$ in Europe, and followed by $(44.6 \%)$ in Asia $(7.4 \%)$, in North America $(0.9 \% \%)$, in South America $(0.4 \%)$, in Africa and last but not the least in Australia (0.26\%).

The findings of different studies showed that there was significantly increased the confirmed COVID-19 cases by 109,555 in Asia, 8,658 in Africa, 332,866 in North America, 20,269 in South America, 568,894 in Europe, 5,051 in Australia and 1,045,403 in the whole world continents except Antarctica from 20 March 2020 to 3 April 2020. There was increased the total recovery and discharged COVID-19 patients from Hospital and other COVID-19 emergency management centers by 37,026 in Asia, 821 in Africa, 18,231 in North America, 2,150 in South America, 111,682 in Europe, 609 in Australia and 170,519 in the whole world except Antarctica [5].

Table 6 indicated a total of 64,942 death was recorder due to COVID-19 from December 2019 to April 5,2020. From those, the majority 46,194 $(71.1 \%)$ were in Europe, and followed by $8,972(13.8 \%)$ were in North America, 8,335 (12.8\%) in Asia, 822 (1.27\%) in South America, $385(0.6 \%)$ in Africa and only $34(0.05 \%)$ in Australia; however, still there was no any registered death and case in Antarctica. Regarding to speed re- lated with deaths could not been resisted with a world health professionals and governments, because the finding showed that there was increased the total death due to COVID-19 at home and health facilities by 4,393 in Asia, 348 in Africa, 8,968 in North America, 765 in South America, 43,991 in Europe, 29 in Australia and 58,624 in the whole world except Antarctica from 20 March 2020 to 3 April 2020.

The closed cases which had an outcome and recovery and discharged and deaths in a world continents ability to implement quarantine as prevention and control way and supportive treatment including isolation as best way to slow transmission is examined, it is clear that death due to COVID-19 pandemic diseases are increasing mental health related outcome. Most of the world communities are under high grade stressed due to the increment of territories (Table 7). The results also shown that the COVID-19 outbreak disease was occurred at Wuhan city of China since 31 December 2019. However, the problem are disseminated to world countries and there was an indicator which addressed a significantly increase the territories up to 3 April 2020.

Most of increments of territories were seen in Europe and Africa which have the same value, 54 (25.8\%), and followed by Asia 47 (22.5\%), North America 40 (19.1\%) and South America 14 (6.7\%). However, there 
Table 6

Death due to COVID-19 reports between 1 January 2020 to 20 March 2020 and 1 Januray 2020 to 3 April 2020

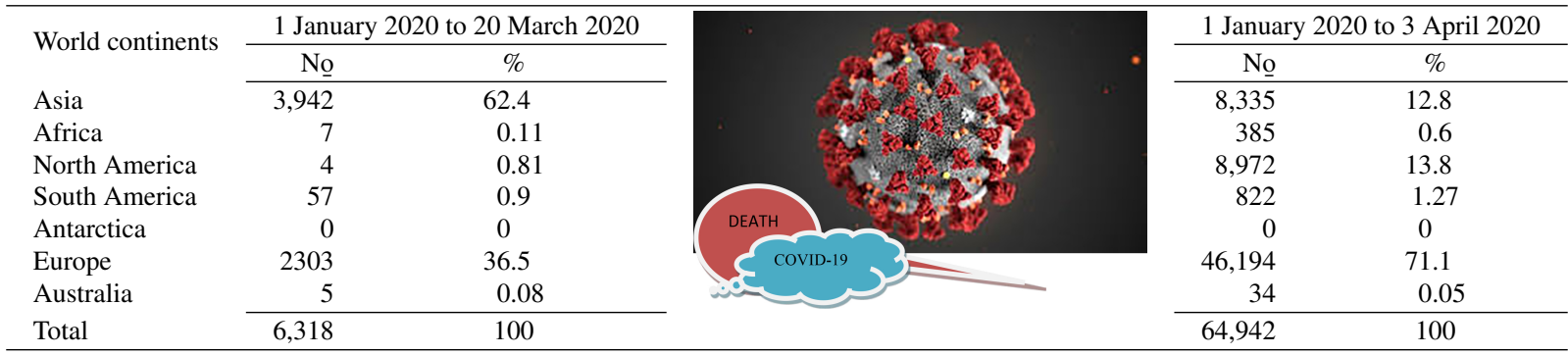

Source: [8].

Table 7

Territories reports between 1 January 2020 to 20 March 2020 and 1 Januray 2020 to 3 April 2020

\begin{tabular}{|c|c|c|c|c|}
\hline \multirow{2}{*}{ World Continents } & \multicolumn{2}{|c|}{1 January 2020 to 20 March 2020} & \multicolumn{2}{|c|}{1 Januray 2020 to 3 April 2020} \\
\hline & Nọ & $\%$ & No & $\%$ \\
\hline Asia & 41 & 29.9 & 47 & 22.5 \\
\hline Africa & 26 & 18.9 & 54 & 25.8 \\
\hline North America & 12 & 8.8 & 40 & 19.1 \\
\hline South America & 14 & 10.2 & 14 & 6.7 \\
\hline Antarctica & 0 & 0 & 0 & 0 \\
\hline Europe & 44 & 32.1 & 54 & 25.8 \\
\hline Australia & 0 & 0 & 0 & 0 \\
\hline Total & 137 & 100 & 209 & 100 \\
\hline
\end{tabular}

Source: [8].

Table 8

Location, origin, and first case of COVID-19, SARS-CoV-2 observed in the world from 1 Januray 2020 to 26 Feburary 2020

\begin{tabular}{clll}
\hline S.No & Location & Origin [First outbreak: Index Cases] & Date, month and year of first case \\
\hline 1 & Asia & Wuhan, Hubei, China: NA & 31 December 2020 \\
2 & Africa & Wuhan, Hubei, China: Cairo, Egypt & 14 Feburary 2020 \\
3 & North America & Wuhan, Hubei, China: Snohomish, Washington, United States & 21 January 2020 \\
4 & South America & Wuhan, China: Saa Paulo, Brazil & 26 Feburary 2020 \\
5 & Antarctica & NA: NA & NA: NA \\
6 & Europe & Wuhanm Hubei, China: Bordeaux, France & 21 January 2020 \\
7 & Australia & Unknown: Melboume, Victoria & 25 Januray 2020 \\
\hline
\end{tabular}

Source: [8].

was no any change and registered territories increment and decrement in the world. Regarding to the difference from month to month reports about the territories, there was increased the total territories vulnerable with Novel COVID-19 by 6 in Asia, 28 in Africa, 28 in North America, 10 in Europe, and 72 in the whole world except Antarctica, South America and Australia from 20 March 2020 to 3 April 2020.

Table 8 shows that most of world continents have reported COVID-19; SARS-CoV-2 since 31 December 2019 starting from Wuhan, Hubei, China without any index cases. However, Antarctica is the only world continent not yet reported COVID-19-SARS-CoV-2 [9,10]. In addition, the finding shown that most of continent have affected with this virus on January and Feburary; however, the spread of COVID-19 case are exacerbated with various factors and to be reached at high risk level among the world socioeconomic and health impacts.

\section{Discussions}

The governments, health care providers and any sectors professionals' concerns about the current pandemic COVID-19 transmission and its adverse consequences of health system change on addressing the adequate medical care for those who are confirmed COVID-19 and suspected cases of communities related to COVID19 including quality testing process at diagnostic laboratory centers are differ from country to country. This 
study is describes the active cases including currently infected or confirmed patients, mild condition, sever or critical condition; and closed cases which included that case that had an outcome, recover and /or discharged and death, territories, location, origin and first or index cases and overall management system for COVID-19 in world continents $[1,11]$.

Currently, China has successfully implemented the efficient and effective the five major WHO prevention and control methods to slow COVID-19 transmission from person to person as since the first attacked on 31 December 2019, with more than 81,554 confirmed cases, 59,38 cases in 1 million people, 76,238 recovered and 3,312 deaths due to this disease. The epidemic and pandemic prone disease outbreak threaten community and public health security in a world continents except Antartica up to 3 April 2020. The COVID-19 is responsible increase number of cases and deaths, mild and severe level of morbidity as well as increasing number of deaths in the world. The COVID-19 has devastating impact of social, physiological and economic status of all countries in world continents. Moreover, COVID-19; SARS-CoV-2 as a pandemic disease outbreak can occur across the world and affect every nation and community health status but, also increasing death rate without expected time frame. Currently, most of world continents, each region and countries have reported the COVID-19 as pandemic. Among those, most of the countries designed integrated management and WHO major prevention and control methods were setup to address the burden of COVID-19 and improve the availability and use of WHO rule and regulation so as to slow COVID-19, and detecting and responding to community health effects $[2,12]$.

The review provided that strong evidence that making WHO prevention and control methods like quarantine, surevillence, isolation and managing of COVID-19 were implemented to slow COVID-19 transmission in the world. However, in Antartica, totally restricts human movements which helps to prevent the spread of COVID-19, and its consequence (Australian Antartic Division, 2019). Similarily, British Antartic Survey [7] suggested that Antartica is one of the world continents which has been implementing the major prevention and control methods. In addition immediate quarantine was implemented after the first COVID-19 case has been occurred in Wuhan, Hebie city of China.

The review also showed that both active and closed COVID-19; SARS-CoV-2 cases significantly increasing time to time due to lack of communities' and health care providers' awareness, negative attitudes, ignorance and shortage of waiting centers and areas to isolate confirmed as well as suspected cases related with travelers, visters and new comers from various countries [13].

Every country in the world need an emergency national set of standard measures, appropriate use of an evidence based prevention and control methods, prepare common COVID-19 management guideline based on severity of the cases, and collaboration as joint activities among all partners. As aresult, different supports have provided through governmental and nongovernmental organizations including higher level of fund raisers and grantors. These could help to slow transmission of COVID-19 and decreases deaths [14]. However, the review showed that there was increasing COVID-19 confirmed cases and deaths in every seconds. An emergency national and international set of stnadrd measures would also allow all health settings to have some confidence to held accountable management for those confirmed, suspected and emergent COVID19 patienrs appropriately and carefully. Moreover, it helps to minimize the cross cut of this pandemic disease from country to countries and from indivividual to anothers $[15,16]$.

\section{Conclusions}

The review concluded that COVID-19; SARS-CoV-2 is the major global public health burden due to its dramatically increase of morbidity and mortality rate from time to time. However, China has shown promising reduction of COVID-19 transmission by forming strong collaboration among all sectors and the design of effective prevention and control strategies which include staying at home, social/physical distancing, quarantine, testing of suspected patients, isolation and managing of the confirmed cases. Therefore, other countries of the world should have also taken an intersecterial, interasectoral and launched WHO five major COVID19 effective and efficient prevention and and control programmes to address the immediate and underlying causes of this disease especially at Community level.
Abbreviations
CDC Center of Disease Control
COVID-19 Novel Coronavirus Disease 2019
SARS-CoV Severe Acute Respiratory Syndrome Coronavirus
MERS-CoV Middle East Respiratory Syndrome Coronavirus
WHO World Health Organization 


\section{Author contributions}

All authers contributed equally during the title selection, design, statistical analysis, and interpretation of results. They are also involved in the review by giving suggestions, comments, support, encouragement, and contribution throughout the review. All authors read and have approved this manuscript to be published.

\section{Acknowledgments}

We would like to express our gratitude to Salale University for logistic support during the review. All individuals who render help in this review are highly acknowledged.

\section{References}

[1] N. Chen, M. Zhou, X. Dong, J. Qu, F. Gong, Y. Han, Y. Qiu, J. Wang, Y. Liu, Y. Wei et al., Epidemiological and clinical characteristics of 99 cases of 2019 novel coronavirus pneumonia in Wuhan, China: A descriptive study, Lancet (2020).

[2] T. Singhal, A review of coronavirus disease-2019 (COVID19), Indian J Pediatr 2020 Apr 87(4) (2020), 281-286. doi: 10.1007/s12098-020-03263-6.

[3] H. Chaolin, W. Yeming, L. Xingwang, R. Lili, Z. Jianping, H. Yi et al., Clinical features of patients infected with 2019 novel coronavirus in Wuhan, China. Published Online January 24 2020 (2020), 30183-30185, doi: 10.1016/S0140-6736(20).

[4] F.W.C. Jasper, Y. Shuofeng, K. Kin-Hang, K.W.T. Kelvin, C. Hin, Y. Jin et al., A familial cluster of pneumonia associated with the 2019 novel coronavirus indicating person-to-person transmission: A study of a family cluster. Published Online January 24, 2020 (2020), 30154-30159. doi: 10.1016/S0140$6736(20)$.

[5] World Health Organization, Director-General's remarks at the media briefing on $2019-\mathrm{nCoV}$ on 11 February 2020. https://www.who.int/dg/speeches/detail/who-directorgeneral-s-remarks-at-the-media-briefing-on-2019-ncov-on11-february-2020 [Accessed on February 12, 2020].

[6] J. Yang, Y. Zheng, X. Gou, K. Pu, Z. Chen, Q. Guo, R. Ji, H. Wang, Y. Wang and Y. Zhou, Prevalence of comorbidities in the novel Wuhan Coronavirus Disease 2019 (COVID-19) infection: A systematic review and meta-analysis. International Journal of Infectious Diseases 2020, doi: 10.1016/j.ijid. 2020.03.017.

[7] British Antarctic Survey, British Antarctic Survey response to COVID-19, March 24, (2020). [Accessed on April 04, 2020].

[8] https://www.worldometers.info/coronavirus/\#countries [Accessed on March 24, 2020].

[9] A. Adam and P. Stefano, One continent remains untouched by the coronavirus: Antarctica. The Washington Post, March 24, (2020). [Accessed on April 2, 2020].

[10] T. Elle, What life is like on Antarctica, the only continent without a case of coronavirus. ABC News, (20 March 2020) [Accessed on April 3, 2020].

[11] K. Kensaku, K. Hajime, Y. Takuya, M. Tamano, S. Motoi and W. Takaji, Initial investigation of transmission of COVID-
19 among crew members during quarantine of a Cruise Shi, Yokohama, Japan, (February 2020).

[12] C.C. Lai, C.Y. Wang, Y.H. Wang, S.C. Hsueh, W.C. Ko and P.R. Hsueh, Global epidemiology of coronavirus disease 2019: Disease incidence, daily cumulative index, mortality, and their association with country healthcare resources and economic status. Int J Antimicrob Agents (18 Mar 2020), 105946. doi: 10.1016/j.ijantimicag.2020.105946.

[13] Centers for Diseases Control and Prevention, 2019 Novel Coronavirus (2019-nCov) situation summary: Archived from the original on 26, January, 2020 [Accessed March, 15, 2020].

[14] P.M. Abena, E.H. Decloedt and E. Bottieau, Chloroquine and Hydroxychloroquine for the Prevention or Treatment of Novel Coronavirus Disease (COVID-19) in Africa: Caution for Inappropriate Off-Label Use in Healthcare Settings [published online ahead of print, 2020 Apr 22]. Am J Trop Med Hyg. (2020); 10.4269/ajtmh. 20-0290. doi: 10.4269/ajtmh.20-0290.

[15] Z.L. Chen, Q. Zhang, Y. Lu, Z.M. Guo, X. Zhang, W.J. Zhang, C. Guo, C.H.J. Liao, Q.L. Li, X.H. Han and J.H. Lu, Distribution of the COVID-19 epidemic and Correlation withpopulation emigration from Wuhan, China. Chin med J (Engl), Feb 28 (2020), Pii: 10.1097/CM9.0000000000000782.

[16] European Centre for Disease Prevention and Control, Rapid risk assessment: Outbreak of novel coronavirus disease 2019 (COVID-19): Increased transmission globally-fifth update, (2020). https://www.ecdc.europa.eu/sites/default/files/ documents/RRA-outbreak-novel coronavirus-disease2019increase-transmission-globally-COVID19.pdf [Accessed on April 20, 2020]

\section{Annex: Research team members perception and suggestion}

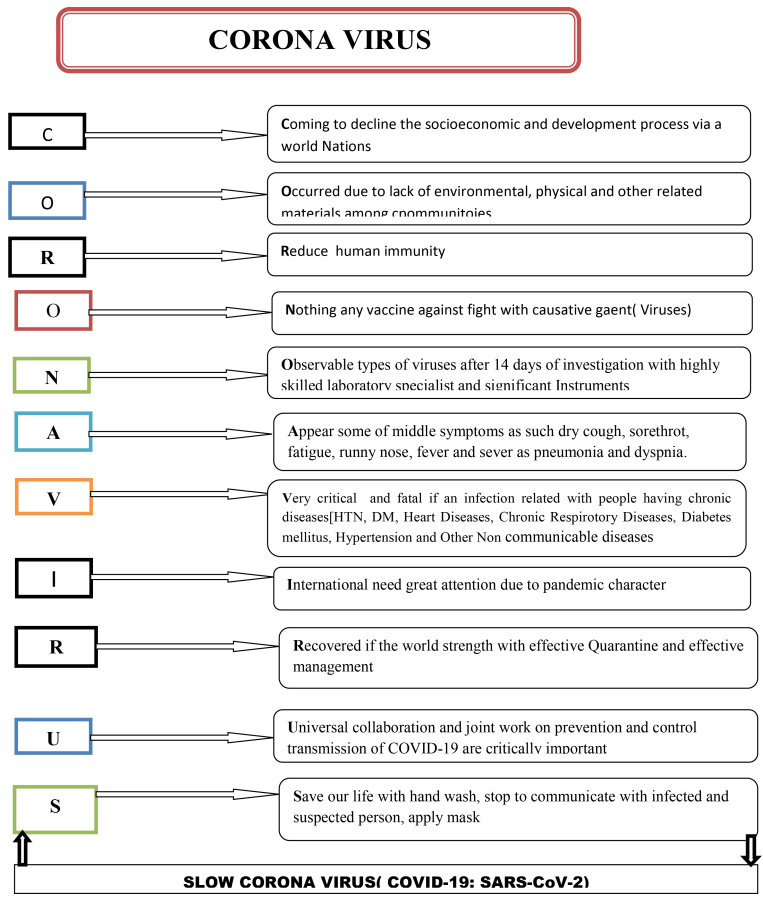

